\title{
High Energy Efficiency Test System for Induction Heating Generators
}

\author{
V. Esteve ${ }^{1}$, J. Jordán ${ }^{1}$, E. J. Dede ${ }^{1,2}$, E. Sanchis-Kilders ${ }^{1}$ and E. Maset ${ }^{1}$ \\ ${ }^{1}$ Department of Electronic Engineering \\ ETSE, University of Valencia \\ Dr. Moliner 50, \\ E.-46100 Burjassot, Spain \\ e-mail: vesteveg@uv.es \\ ${ }^{2}$ Department of Research and Development \\ GH Electrotermia S.A. \\ Vereda Real s/n \\ E-46184, S. Antonio de Benageber, Spain \\ e-mail: ghe@ghe.es
}

\begin{abstract}
Power supplies used in induction heating industrial applications must be entirely tested after its manufacturing in order to assure its security and reliability by means of a full power running test of several hours of duration. Nowadays this test is done with a dissipative load which implies a large waste of energy. This paper proposes a new high efficiency test system for induction heating generators. It incorporates a regenerative electronic load which allows an extraordinary improvement of the efficiency of this test with an important economical and ecological benefit.
\end{abstract}

\section{Key words}

Energy conversion. Energy efficiency. Energy saving policy. Induction heating generators. Industry applications.

\section{Introduction}

Power electronics systems used like power supplies in induction heating applications are inverter circuits, usually called "generators", with sinusoidal waveform output of frequency in the range of $500 \mathrm{~Hz}$ to $500 \mathrm{kHz}$ depending on the application. The output power of these generators can vary, also depending of the application, from several kilowatts to tens of megawatts [1]. Generators must be tested during several hours in the final phase of its manufacturing process in order to assure its security and reliability.

The output power of an induction heating generator is transmitted (induced) to any metallic part which is in the proximity of the heating inductor. This induced energy produces the heating of the part's surface in a fast and controlled way. This heating effect is used in several industrial applications of special industry like fusion, forging, hardening, etc. [2]

Fig. 1 shows the schematic diagram of a classical running test of an induction heating generator. During the tests of the heating installation the whole output power is dissipated. Liquid fluid cooled loads are normally used in order to prevent an excessive rise of the temperature.

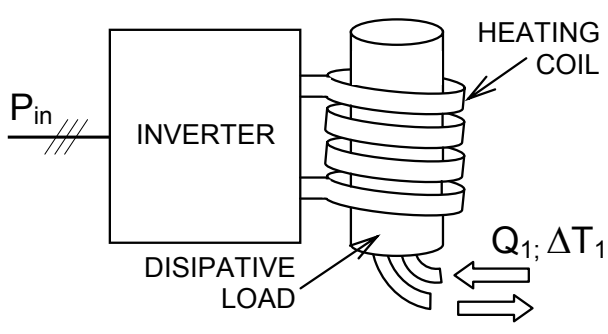

Fig. 1: Classical induction heating generator test configuration.

This allows to transfer the power delivered to the load to the cooling fluid which usually flows in closed circuit. If his fluid is water the following expression is fulfilled: [3]

$$
P_{P}=69 Q_{1} \Delta T_{1}
$$

where $P_{P}$ is the dissipated power expressed in watts (W), $\mathrm{Q}_{1}$ is the water flow expressed in liters by minute $(1 / \mathrm{min})$ and $\Delta T_{1}$ is the increase of the water temperature during the refrigeration of the load. An adequate external heat exchanger system allows maintaining temperature of the input cooling water.

The process described in the previous paragraph has zero energy efficiency and a maximum economical cost because all the energy is lost (dissipated in heat form). Additionally, this cost must be incremented by the power consumed by the closed circuit water pumps, the heat exchanger and the cooling tower. On the other hand, there is an ecological damage due to high consumption of water.

An equivalent circuit of the heating inductor and the dissipative load can be the series connection of an inductance $\mathrm{L}$ with a value equal to the heating inductor reactive impedance and a resistance $R_{\text {eq }}$ value whose corresponds to the resistive losses of the circuit (inductor resistance, connections and dissipative load). This resistance originates the dissipation by Joule effect $\left(\mathrm{i}_{\mathrm{L}}{ }^{2} \mathrm{R}_{\mathrm{eq}}\right)$ of the power delivery by the induction heating generator. 


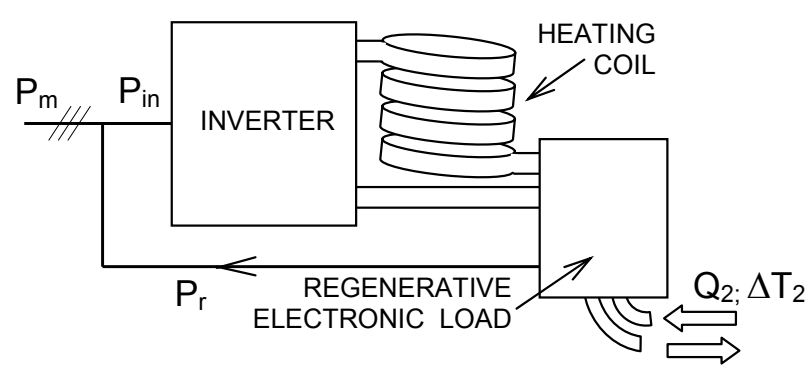

Fig. 2: Proposed test configuration.

Fig. 2 shows a new test configuration which allows an extraordinary improvement of the efficiency of this test with an important economical and ecological benefit. In this case the heating inductor does not have any dissipative load inside and there is a new converter which is connected in series. This new device acts like a regenerative electronic load because it simulates a resistive impedance which absorbs the power induced by the heating inductor and delivers the most part of this energy to the mains, improving in this way the overall efficiency of the test [4]. Now the cooling magnitudes $\mathrm{Q}_{2}$ and $\Delta \mathrm{T}_{2}$ are used only to evacuate the losses of the regenerative electronic load which are much smaller than the one present in the classic test configuration.

\section{System configuration}

Fig. 3 shows the general block diagram of the induction heating test configuration using the proposed solution. The input of the regenerative electronic load (1) is connected to the output (4) of the induction heating generator under test (2) and the output (7) is connected to the mains (3) to where the most part of the output power of the generator is returned during the test. The regenerative electronic load is constituted by an input converter (5) that matches the voltage and current delivered by the generator under test, an output converter (6) that is connected to the mains to return the power and a controller block (8) which manages the input and output information in order to assure the configuration, instrumentation and communication processes (9).

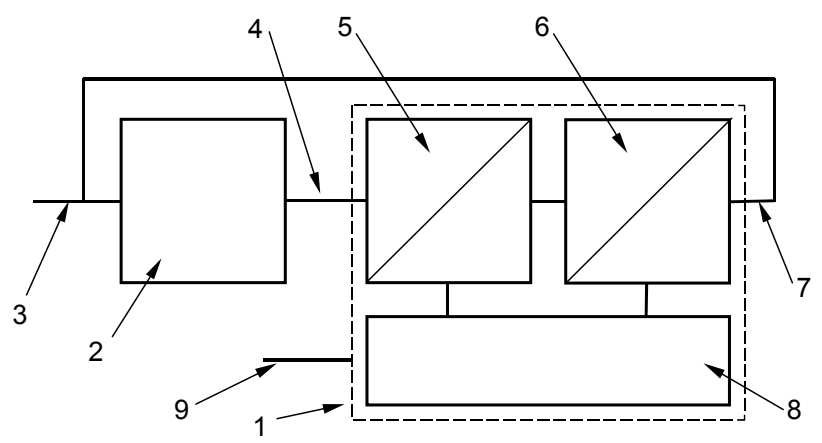

Fig. 3: General block diagram

The simplified schematic of the prototype of the regenerative electronic load is shown in Fig. 4. The series connection with the heating inductor is made using a matching transformer (1), a non controlled rectifier bridge (2) and a boost converter (3) which transforms the ac current at the output of the induction heating generator into continuous voltage [5] that is regulated by means of the control circuit (8). A three-phase full bridge inverter (4) and an output transformer (5) are used in order to return the power to the mains (6). The switching sequence of the inverter transistors is made by means the control circuit (7).

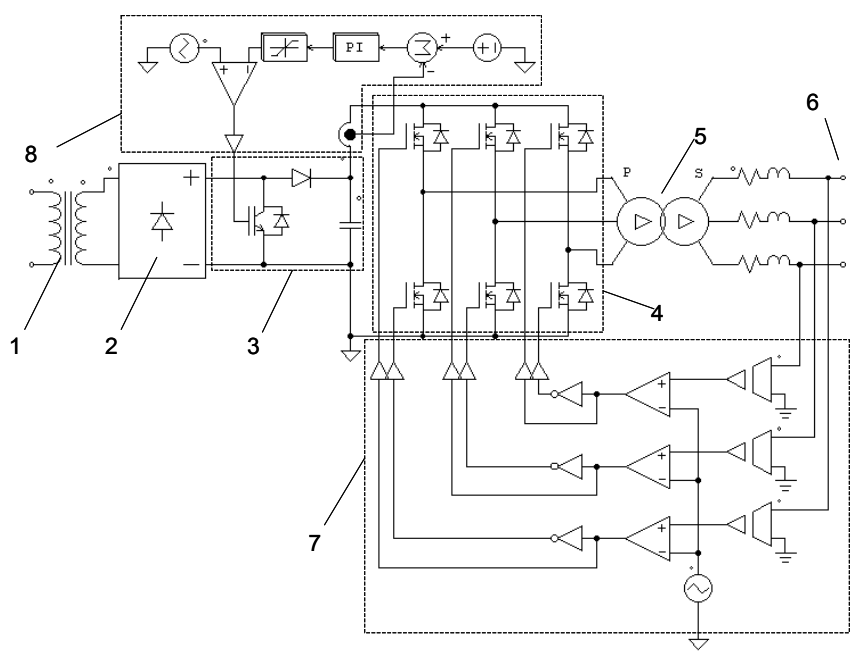

Fig. 4: Simplified schematic of the regenerative electronic load.
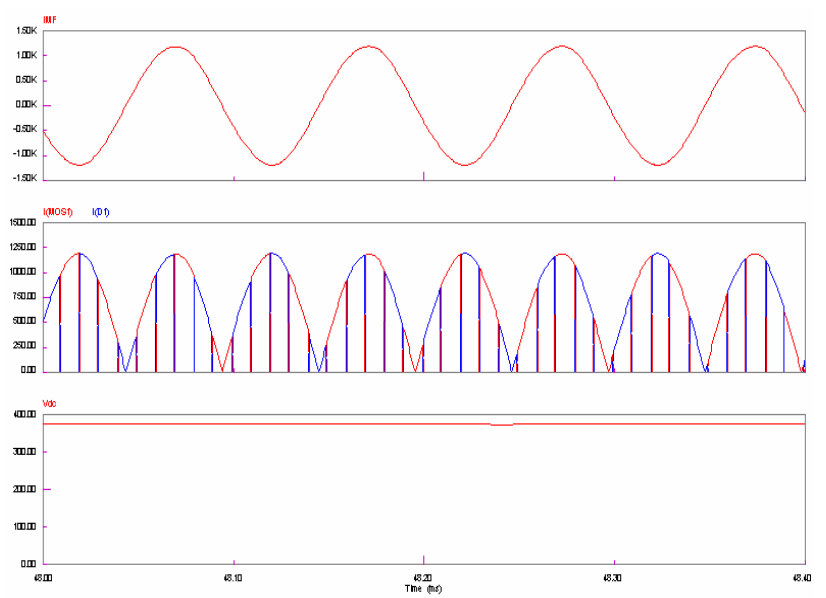

Fig. 5: Output current of the DUT (upper red trace).

Transistor and diode current (middle red and blue traces) and output voltage (lower red trace) of the input boost converter.

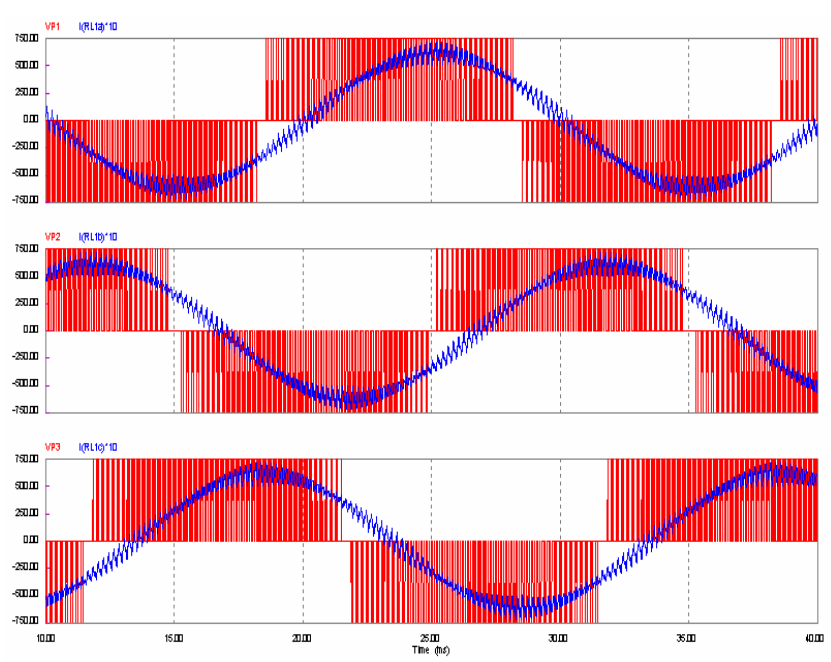

Fig. 6: Output current (blue trace) and output voltage (red trace) of the output inverter. 


\section{Experimental results}

A regenerative electronic load will be made in order to make the running test of an induction heating generator of $100 \mathrm{~kW}$ of output power connected to the $400 \mathrm{~V}$, $50 \mathrm{~Hz}$ three-phase utility power system used in Europe. The output frequency of the generator was approximately $10 \mathrm{kHz}$. The regenerative electronic load has an input boost converter with low switching losses IGBT transistors working at a frequency of $50 \mathrm{kHz}$. The output inverter stage has also IGBT transistors working at $5 \mathrm{kHz}$ switching frequency. The input transformer is made with water cooled copper tube and with ferrite core. The air cooled output transformer and output filter were designed in order to get a total harmonic distortion less than $1 \%$. The predicted efficiency of the whole circuit is larger than $80 \%$ when the output power is larger than $50 \%$ of the maximum value.

\begin{tabular}{|l|c|c|}
\cline { 2 - 3 } \multicolumn{1}{l|}{} & $\begin{array}{l}\text { CLASSICAL TEST } \\
\text { CONFIGURATION }\end{array}$ & $\begin{array}{c}\text { PROPOSED TEST } \\
\text { CONFIGURATION }\end{array}$ \\
\hline $\begin{array}{l}\text { INDUCTION HEATING } \\
\text { GENERATOR POWER } \\
\text { LOSSES }\end{array}$ & $12 \mathrm{~kW}$ & $12 \mathrm{~kW}$ \\
\hline $\begin{array}{l}\text { DISSIPATIVE LOAD } \\
\text { POWER LOSSES }\end{array}$ & $100 \mathrm{~kW}$ & $19 \mathrm{~kW}$ \\
\hline $\begin{array}{l}\text { REGENERATIVE } \\
\text { ELECTRONIC LOAD } \\
\text { POWER LOSSES }\end{array}$ & $112 \mathrm{~kW}$ & $27 \mathrm{~kW}$ \\
\hline $\begin{array}{l}\text { TOTAL POWER } \\
\text { LOSSES }\end{array}$ & $0 \%$ & $72 \%$ \\
\hline $\begin{array}{l}\text { TOTAL TEST } \\
\text { EFFICIENCY }\end{array}$ & $821 / \mathrm{min}$ & $201 / \mathrm{min}$ \\
\hline $\begin{array}{l}\text { COOLING WATER } \\
(\Delta T=20 K)\end{array}$ & $112 €$ & $27 €$ \\
\hline $\begin{array}{l}\text { TEST COST }(10 \text { hours } \\
\text { test })\end{array}$ & & \\
\hline
\end{tabular}

Table 1: Comparative results for the running test of an induction heating generator with an output power of $100 \mathrm{~kW}$.
Simulation tests were made in order to carry out the comparison between the classic test configuration and the proposed solution. An important saving of energy, money and cooling water was verified. Table 1 shows these results. In future versions of this paper we will give more details about the experimental method, test conditions, photographies, experimental waveforms, etc.

\section{Conclusions}

The made tests have demonstrated the viability of the proposed solution. The system described in this paper is patented by the authors [4]. New investigations will be made in order to get the design of alternative topologies of the input converter of the regenerative electronic load with the aim of to obtain improvements of operation and to increase the versatility and the controllability of the system.

\section{Acknowledgments}

The authors would like to thank GH Electrotermia S.A. and Generalitat Valenciana which has supported this work with the project ref: GRUPOS2005-076.

\section{References}

[1] N. Mohan, T. Underland, W. Robbins. "Power Electronics". John Wiley \& Sons, Inc.

[2] E.J. Davies. "Conduction and Induction Heating". IEE Power Engineering Series II. Peter Peregrinus Ltd.

[3] M. Fishenden, O.A. Saunders "An Introduction to Heat Transfer" Oxford University Press. Oxford.

[4] V. Esteve, J. Jordán. "Sistema estático de cogeneración y ensayo para fuentes de alimentación de alta potencia". Patent number P20020187.

[5] Jin-Hyoe Kim, D. Y. Lee, H. S. Choi and B. H. Cho, "High Performance Boost PFP (Power Factor Preregulator) with an improved ZVT converter", in APEC 2001 , pages 337-342. 